\title{
Overactive Bladder Successfully Treated with Duloxetine in a Female Adolescent
}

\author{
Sheng-Min Wang ${ }^{1,2}$, Hae-Kook Lee ${ }^{3}$, Yong-Sil Kweon ${ }^{3}$, Chung Tai Lee ${ }^{3}$, Kyoung-Uk Lee ${ }^{3}$ \\ 'Department of Psychiatry and 'International Health Care Center, Seoul St. Mary's Hospital, The Catholic University of Korea College of \\ Medicine, Seoul, 'Department of Psychiatry, Uijeongbu St. Mary's Hospital, The Catholic University of Korea College of Medicine, Uijeongbu, \\ Korea
}

\begin{abstract}
Overactive bladder $(\mathrm{OAB})$ is defined as urgency, usually with frequency and nocturia, and with or without urge incontinence. Duloxetine, an antidepressant that inhibits reuptake of serotonin and norepinephrine, is indicated for the treatment of stress urinary incontinence in Europe. In this paper, we present a case of a 17-year-old female patient with OAB and depressive symptoms who was successfully treated with duloxetine. This case suggests duloxetine can be an option for patient with OAB, and it also highlights the need for further studies of duloxetine's use in the treatment of OAB.
\end{abstract}

KEY WORDS: Duloxetine; Overactive urinary bladder; Treatment; Stress urinary incontinence; Depression.

\section{INTRODUCTION}

Overactive bladder (OAB) is a urological condition defined by a symptom complex, which includes urgency, usually with frequency and nocturia, and with or without urge incontinence. ${ }^{1)}$ Frequency is generally defined as urinating more than eight times a day.

Duloxetine, a dual reuptake inhibitor of serotonin and norepinephrine, is approved for the treatment of major depressive disorder, generalized anxiety disorder, diabetic peripheral neuropathic pain, fibromyalgia, and chronic musculoskeletal pain in the US. ${ }^{2)}$ In Europe, duloxetine is also indicated for the treatment of stress urinary incontinence in women. ${ }^{3,4)}$ Although studies have suggested that duloxetine may be effective in treating $\mathrm{OAB}$, its use in this condition is still not indicated. ${ }^{5,6)}$ More importantly, the effectiveness of duloxetine in $\mathrm{OAB}$ patients with purely irritative symptoms (i.e., OAB without stress or urge incontinence) remains unknown. In this paper, we report a case of $\mathrm{OAB}$ without stress and urge incontinence complicated by depressive symptoms in an adolescent female that was successfully treated with duloxetine.

\footnotetext{
Received: December 5, 2014 / Revised: January 12, 2015 Accepted: January 23, 2015

Address for correspondence: Kyoung-Uk Lee, MD, PhD Department of Psychiatry, Uijeongbu St. Mary's Hosptial, The Catholic University of Korea College of Medicine, 271 Cheonbo-ro, Uijeongbu 11765, Korea

Tel: +82-31-820-3609, Fax: +82-31-847-3630

E-mail: smwang11@daum.net
}

\section{CASE}

A 17-year-old female patient, a high school junior, with no known medical or urogynecological history, presented with urgency and frequency for 2 years. Her frequency was very severe; she had to urinate every 30 to 60 minutes during the day. She also exhibited fear of incontinence, although she had no actual incontinence. These urinary symptoms and related anxiety prevented her from concentrating in class, interfered with daily living, and caused her embarrassment. She stated, "When I get the urge, I must go right away. I can't even get on a bus because I am afraid that I might get the urge while I am on it and embarrass myself." Occasionally, she also had to wake up one to two times during the night because of nocturia.

Before the patient was referred to our psychiatric department, she was treated in our urological department for 5 months. Initial physical examination, urinalysis, and X-rays of the lower abdomen yielded no abnormal findings. Under the urologist's care, she was prescribed solifenacin succinate ( $5 \mathrm{mg}$ /day) for 3 weeks, oxybutynin chloride ( $5 \mathrm{mg} /$ day) for 3 weeks, fesoterodine fumarate $(8$ $\mathrm{mg}$ /day) for 3 months, and propiverine hydrochlroride (20 $\mathrm{mg}$ /day) for 4 weeks. However, her OAB symptoms remained unimproved, leading her to worry that the symptoms were not treatable. She could not sleep at night because of these worries. This anxiety later developed into depression, and she felt agitated and suicidal. Thus, she was referred to our psychiatric department.

(c) This is an Open-Access article distributed under the terms of the Creative Commons Attribution Non-Commercial License (http://creativecommons.org/licenses/by-nc/4.0) which permits unrestricted non-commercial use, distribution, and reproduction in any medium, provided the original work is properly cited. 
Upon referral, she was treated with escitalopram (10 $\mathrm{mg}$ /day) for 5 weeks under impression of depression related to $\mathrm{OAB}$. However, neither her depression nor her OAB showed any signs of improvement. She was then switched to fluoxetine (10 mg/day) for 2 weeks, but this was stopped because her insomnia worsened. Imipramine (20 mg/day) was then prescribed for 3 weeks, but her urinary symptoms worsened. Meanwhile, she became hopeless about her OAB and stopped visiting her urologist. She was then prescribed duloxetine ( $30 \mathrm{mg} /$ day), and the dosage was escalated to $60 \mathrm{mg} /$ day after 5 weeks of titration. Six weeks after duloxetine initiation, she described her urgency and frequency as $50 \%$ better. About a month later, she no longer had nocturia, and her micturition frequency has decreased to every 2 hours during the day, allowing her to concentrate during class. While she was taking duloxetine (60 mg/day), her depressive symptoms including insomnia and agitation also improved along with her alleviation of $\mathrm{OAB}$ symptoms over the next 6 months. Her urination frequency decreased to eight or fewer times a day, and she no longer had trouble with daily living or with riding the bus. She stated that she experienced no urinary urgency while taking the College Scholastic Ability Test, which lasted for more than 6 hours. Complaints of urgency and frequency did not recur and remained absent throughout treatment with duloxetine $(60 \mathrm{mg} /$ day $)$. At the time of submission of this manuscript, she planned to attend college.

\section{DISCUSSION}

To the best of our knowledge, this is the first study reporting a case of a female adolescent having OAB and depression which was successfully treated with duloxetine. A previous study reported a case of detrusor overactivity successfully treated with duloxetine. ${ }^{7)}$ The chief complaint of a 47-year-old female in the report was stress incontinence, which is a current indication for duloxetine. ${ }^{3,4)}$ In contrast, the case reported here affected an adolescent with purely irritative symptoms without stress or urge incontinence. The fact that our patient's OAB was refractory to three anticholinergic medications and three antidepressants, but resolved after duloxetine administration, is also noteworthy.

Studies have suggested that duloxetine improves urinary incontinence by inhibiting reuptake of serotonin and norepinephrine at the pre-synaptic neuron in Onuf's nucleus in the sacral spinal cord. ${ }^{8)}$ Both alpha-receptors and serotonin $5-\mathrm{HT}_{2}$ receptors in Onuf's nucleus facilitate the storage reflex by contracting the urethral external sphincter muscle. ${ }^{9)}$ Furthermore, results of an animal study suggested that duloxetine could increase vesical maximal capacity five fold. ${ }^{10)}$ Duloxetine's ability to increase bladder capacity may be an important contributor to the improvement of urgency and frequency in our case.

We did not perform a urodynamic test, which could be an important limitation because it could have provided a more objective measure of severity of the OAB. We did not perform this test because it is usually indicated in patients with diagnosed or suspected neurological disease, ${ }^{11)}$ and our patient had no evidence of such a condition. Another potential issue is that the safety and effectiveness of duloxetine in pediatric patients have not been established. Nonetheless, its use in children or adolescents is not contraindicated, and recommendations for duloxetine in such patients are to balance potential risks with clinical need. ${ }^{2)}$ Finally, our patient's urinary urgency and frequency may have been a symptom of anxiety, in which case, relief of urinary symptoms was simply a result of the drug's anxiolytic effect. We believe reaching such a conclusion could overlook a patient's disabling urinary symptoms. In line with our belief, studies not only showed association between OAB with anxiety, but also illustrated that people are inclined to consider anxiety symptoms more serious than OAB. ${ }^{12,13)}$ Moreover, constant urinary urges led to anxiety in our patient, so we believed that the anxiety symptoms were secondary to her urgency and frequency.

Regardless of the exact mechanism of successful treatment, our report suggests that duloxetine could be a treatment option for OAB. It also highlights the need for further studies of duloxetine's efficacy in the treatment $\mathrm{OAB}$, especially in those with purely irritative symptoms.

\section{REFERENCES}

1. Wein AJ. Re: An International Urogynecological Association (IUGA)/International Continence Society (ICS) joint report on the terminology for female pelvic floor dysfunction. J Urol 2011;185:1812.

2. Eli Lilly and Company. Highlights of prescribing information. Indianapolis:Eli Lilly;2012.

3. Guay DR. Duloxetine for management of stress urinary incontinence. Am J Geriatr Pharmacother 2005;3:25-38.

4. Millard RJ, Moore K, Rencken R, Yalcin I, Bump RC; Duloxetine UI Study Group. Duloxetine vs placebo in the treatment of stress urinary incontinence: a four-continent randomized clinical trial. BJU Int 2004;93:311-318.

5. Di Rezze S, Frasca V, Inghilleri M, Durastanti V, Cortese A, Giacomelli E, et al. Duloxetine for the treatment of overactive bladder syndrome in multiple sclerosis: a pilot study. Clin Neuropharmacol 2012;35:231-234.

6. Steers WD, Herschorn S, Kreder KJ, Moore K, Strohbehn 
K, Yalcin I, et al; Duloxetine OAB Study Group. Duloxetine compared with placebo for treating women with symptoms of overactive bladder. BJU Int 2007;100:337-345.

7. Basu M, Duckett JR. Detrusor overactivity successfully treated with duloxetine. J Obstet Gynaecol 2007;27:438-440.

8. Jost W, Marsalek P. Duloxetine: mechanism of action at the lower urinary tract and Onuf's nucleus. Clin Auton Res 2004; 14:220-227.

9. Verhamme KM, Sturkenboom MC, Stricker BH, Bosch R. Drug-induced urinary retention: incidence, management and prevention. Drug Saf 2008;31:373-388.

10. Thor KB, Katofiasc MA. Effects of duloxetine, a combined serotonin and norepinephrine reuptake inhibitor, on central neural control of lower urinary tract function in the chloralose-anesthetized female cat. J Pharmacol Exp Ther 1995;274:1014-1024.

11. Nitti V. Clinical testing for overactive bladder. Can Urol Assoc J 2011;5(5 Suppl 2):S137-S138.

12. Milsom I, Kaplan SA, Coyne KS, Sexton CC, Kopp ZS. Effect of bothersome overactive bladder symptoms on healthrelated quality of life, anxiety, depression, and treatment seeking in the United States: results from EpiLUTS. Urology 2012;80:90-96.

13. Nicolson P, Kopp Z, Chapple CR, Kelleher C. It's just the worry about not being able to control it! A qualitative study of living with overactive bladder. $\mathrm{Br} J$ Health Psychol 2008; 13:343-359. 